NASA/TM-2007-214098

\title{
Shear History Extensional Rheology Experiment: A Proposed ISS Experiment
}

Nancy R. Hall and Kirk A. Logsdon

Glenn Research Center, Cleveland, Ohio

Kevin S. Magee

ZIN Technologies, Inc., Brook Park, Ohio 


\section{NASA STI Program . . . in Profile}

Since its founding, NASA has been dedicated to the advancement of aeronautics and space science. The NASA Scientific and Technical Information (STI) program plays a key part in helping NASA maintain this important role.

The NASA STI Program operates under the auspices of the Agency Chief Information Officer. It collects, organizes, provides for archiving, and disseminates NASA's STI. The NASA STI program provides access to the NASA Aeronautics and Space Database and its public interface, the NASA Technical Reports Server, thus providing one of the largest collections of aeronautical and space science STI in the world. Results are published in both non-NASA channels and by NASA in the NASA STI Report Series, which includes the following report types:

- TECHNICAL PUBLICATION. Reports of completed research or a major significant phase of research that present the results of NASA programs and include extensive data or theoretical analysis. Includes compilations of significant scientific and technical data and information deemed to be of continuing reference value. NASA counterpart of peer-reviewed formal professional papers but has less stringent limitations on manuscript length and extent of graphic presentations.

- TECHNICAL MEMORANDUM. Scientific and technical findings that are preliminary or of specialized interest, e.g., quick release reports, working papers, and bibliographies that contain minimal annotation. Does not contain extensive analysis.

- CONTRACTOR REPORT. Scientific and technical findings by NASA-sponsored contractors and grantees.
- CONFERENCE PUBLICATION. Collected papers from scientific and technical conferences, symposia, seminars, or other meetings sponsored or cosponsored by NASA.

- SPECIAL PUBLICATION. Scientific, technical, or historical information from NASA programs, projects, and missions, often concerned with subjects having substantial public interest.

- TECHNICAL TRANSLATION. Englishlanguage translations of foreign scientific and technical material pertinent to NASA's mission.

Specialized services also include creating custom thesauri, building customized databases, organizing and publishing research results.

For more information about the NASA STI program, see the following:

- Access the NASA STI program home page at http://www.sti.nasa.gov

- E-mail your question via the Internet to help@sti.nasa.gov

- Fax your question to the NASA STI Help Desk at 301-621-0134

- Telephone the NASA STI Help Desk at 301-621-0390

- Write to:

NASA STI Help Desk

NASA Center for AeroSpace Information 7115 Standard Drive Hanover, MD 21076-1320 
NASA/TM-2007-214098

AIAA-2006-0524

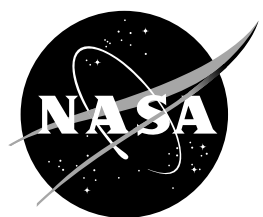

\section{Shear History Extensional Rheology Experiment: A Proposed ISS Experiment}

Nancy R. Hall and Kirk A. Logsdon

Glenn Research Center, Cleveland, Ohio

Kevin S. Magee

ZIN Technologies, Inc., Brook Park, Ohio

Prepared for the

44th Aerospace Sciences Meeting and Exhibit

sponsored by the American Institute of Aeronautics and Astronautics

Reno, Nevada, January 9-12, 2006

National Aeronautics and

Space Administration

Glenn Research Center

Cleveland, Ohio 44135 


\section{Acknowledgments}

The authors would like to thank the team at the NASA Glenn Research Center for the design, fabrication, testing, and documentation associated with this experiment. They also would like to acknowledge Professor Gareth McKinley, principal investigator for the SHERE Globebox Investigation for his insight and numerous discussions pertaining to the areas of nonNewtonian fluids and extensional rheology. The hardware development was supported by NASA under Grant NNC04GA41G.

This report contains preliminary findings, subject to revision as analysis proceeds.

Trade names and trademarks are used in this report for identification only. Their usage does not constitute an official endorsement, either expressed or implied, by the National Aeronautics and Space Administration.

Level of Review: This material has been technically reviewed by technical management.

Available from

NASA Center for Aerospace Information 7115 Standard Drive

Hanover, MD 21076-1320
National Technical Information Service 5285 Port Royal Road Springfield, VA 22161 


\title{
Shear History Extensional Rheology Experiment: A Proposed ISS Experiment
}

\author{
Nancy R. Hall and Kirk A. Logsdon \\ National Aeronautics and Space Administration \\ Glenn Research Center \\ Cleveland, Ohio 44135 \\ Kevin S. Magee \\ ZIN Technologies, Inc. \\ Brook Park, Ohio 44142
}

\begin{abstract}
The Shear History Extensional Rheology Experiment (SHERE) is a proposed International Space Station (ISS) glovebox experiment designed to study the effect of preshear on the transient evolution of the microstructure and viscoelastic tensile stresses for monodisperse dilute polymer solutions. Collectively referred to as "Boger fluids," these polymer solutions have become a popular choice for rheological studies of non-Newtonian fluids and are the non-Newtonian fluid used in this experiment. The SHERE hardware consists of the Rheometer, Camera Arm, Interface Box, Cabling, Keyboard, Tool Box, Fluid Modules, and Stowage Tray. Each component will be described in detail in this paper. In the area of space exploration, the development of in-situ fabrication and repair technology represents a critical element in evolution of autonomous exploration capability. SHERE has the capability to provide data for engineering design tools needed for polymer parts manufacturing systems to ensure their rheological properties have not been impacted in the variable gravity environment and this will be briefly addressed.
\end{abstract}

\section{Nomenclature}

$\begin{array}{ll}D & \text { displacement } \\ \varepsilon & \text { Hencky strain } \\ \dot{\varepsilon} & \text { extensional strain rate } \\ F & \text { force } \\ g & \text { gravity } \\ L_{o} & \text { initial length } \\ R_{o} & \text { initial radius } \\ R_{\text {mid }} & \text { midpoint diameter } \\ T & \text { temperature } \\ t & \text { time } \\ V(t) & \text { stretch velocity } \\ V_{f} & \text { final stretch velocity } \\ \Omega & \text { pre-rotation (pre-shear) rate } \\ \mu & \text { viscosity }\end{array}$

\section{Introduction}

The resistance of a fluid to an imposed flow is termed "viscosity," and it is a fundamental material parameter by which manufacturers and end-users characterize a material. Normally, researchers place a material in a commercial instrument that imposes a simple shearing flow, which reports a rate-dependent shear viscosity. While this level of characterization is sufficient for some processes, in typical industrial polymer processing operations, the material experiences a complex flow history with both shear and extensional kinematic characteristics. For example, in fiber spinning, the fluid experiences a complex transient shear flow as it flows through the spinneret head before entering a region of dominant uniaxial elongation in the spinline. In injection molding, the fluid is sheared in the extruder before transient uniaxial acceleration into the "gates" and cylindrical runners of the die (ref. 1).

Polymer behavior under these conditions is process-dependent and stems from their long chain structure. Polymers are typically hydrocarbon-based molecules composed of repeated molecular units (repeat units) and can 
contain hundreds to tens of thousands of repeat units. The resulting long molecular chain is usually very flexible, allowing the polymer to coil, extend, and entangle with neighboring polymer chains. In its rest state, a typical polymer chain will assume a random coiled configuration. When exposed to a shearing flow, this coil will extend slightly and deform into an elliptical shape aligned $45^{\circ}$ to the flow direction. It will then flip over, repeating this action again and again in the flow. When the polymer is exposed to an extensional flow, the coil extends uniaxially and can be pulled taut if the flow is strong enough. Because polymers act like springs, more stress is required to stretch them to higher strains. This relationship between stress and extensional deformation rate (i.e., strain rate) is expressed as an extensional viscosity and is a fundamental material parameter independent of shear viscosity (ref. 1).

Due to the coiling effect of shear flow on the polymer chains, shearing on the fluid immediately before extension will have an effect on the extensional behavior of the fluid. Therefore, the main objective of the Shear History Extensional Rheology Experiment (SHERE) is to study the effect of preshear on the extensional behavior of the fluid. Specifically, of interest is the transient evolution of the microstructure and viscoelastic tensile stresses that are present during the extension of the fluid.

\section{Science Objectives}

\section{A. Overview}

The combination of both shearing and extensional flows is common in many polymer processing operations such as extrusion, blow-molding and fiber spinning. Therefore, knowledge of the complete rheological properties of the polymeric fluid being processed is required in order to accurately predict and account for its flow behavior. In addition, if numerical simulations are to serve as a priori design tools for optimizing polymer processing operations, then it is critical to have an accurate knowledge of the extensional viscosity and its variation with temperature, concentration, molecular weight, and strain rate.

Unlike Newtonian fluids, complex fluids such as polymers cannot be characterized by a single material parameter such as the Newtonian viscosity, $\mu$. Instead, they exhibit non-linear responses to imposed deformations. Constitutive models have shown the extensional function of non-Newtonian fluids are not constant but depend on both the rate of deformation and the total strain experienced by a fluid element.

A class of dilute polymer solutions collectively referred to as "Boger fluids," have become a popular choice for rheological studies of non-Newtonian fluids and will used in this experiment. These ideal elastic fluids exhibit a nearly constant shear viscosity, which allows a direct comparison of Boger fluids with Newtonian fluids having similar viscosities. The high viscosity of the suspending solvent results in long relaxation times and substantial normal stresses, and the low concentration of high molecular weight polymers facilitates modeling analysis (ref. 2).

\section{B. Justification for Microgravity}

During the experiment, a smooth, bubble-free, cylindrical liquid bridge will be generated between two flat endplates. The liquid bridge will initially be $5 \mathrm{~mm}$ long and $10 \mathrm{~mm}$ in diameter. A homogeneous shear rate will be imposed on the fluid by rotating one endplate at a preselected rate in the range 0 to $500 \mathrm{rpm}$ for a predetermined time while holding the other endplate stationary. As soon as the rotation has stopped, a homogeneous elongational deformation will be imposed by axially translating one of the endplates in an exponential manner to generate constant strain rates in the range of 0.1 to $5.0 \mathrm{~s}^{-1}$. The tensile force and filament shape will be monitored during the elongation, and the elongation will stop at a length of approximately $194 \mathrm{~mm}$.
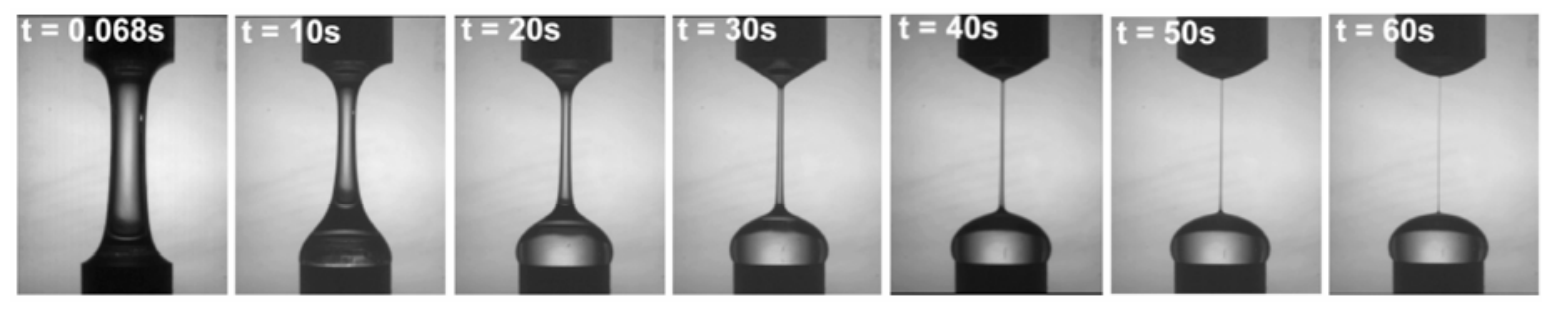

Figure 1.-Newtonian fluid in extensional flow. 


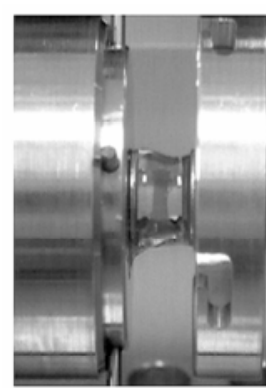

Fluid deployment
Fluid module $\mathrm{KC}-135$ deployment test

Breadboard demonstration of test fluid deployment and stretching in microgravity

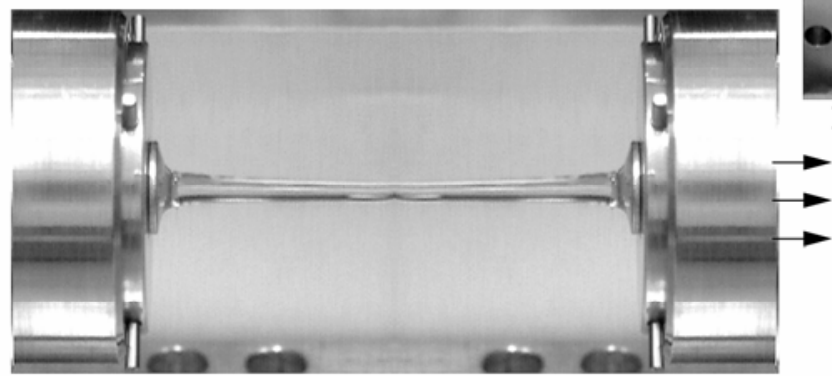

Stretching of a polymeric liquid bridge in microgravity

Figure 2.-Fluid module KC-135 deployment test.

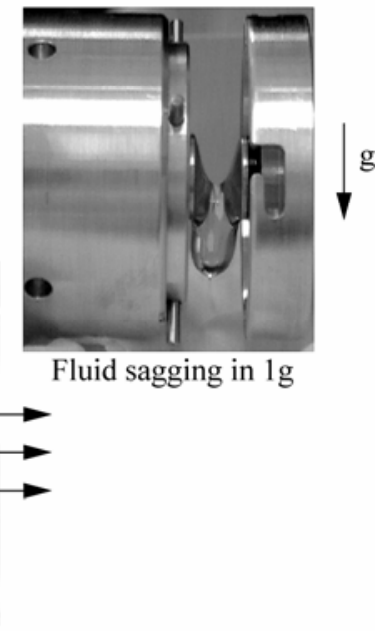

Fluid sagging in $1 \mathrm{~g}$

Once the elongated bridge has stabilized, the experiment will continue to monitor the subsequent evolution of the midpoint radius, filament shape, and tensile force in the column. Eventually, the filament will neck down and break under the combined action of elastic and viscous capillary stresses. Figure 1 shows an example of the evolution of the elongated bridge and its midpoint radius after stretching in a $1 \mathrm{~g}$ environment for a Newtonian fluid.

Gravitational body forces cause appreciable sagging of fluid filaments. This sagging is most notable for low deformation rates where strain-hardening is not significant. Removing these forces will allow one to probe a wider parametric range of strain rates while simultaneously measuring the total stress and velocity field (shape and diameter) of the fluid. These measurements will provide an idealized data set for theoretical model comparison and can serve as a gold standard for ground-based extensional rheometry. Engineering tests of the fluid have been done using NASA's KC-135 Reduced Gravity Airplane. However, the short test time of $20 \mathrm{~s}$ and the jittery microgravity environment precluded obtaining useful science data. Figure 2 shows the fluid deployment test that were performed on NASA’s KC-135.

\section{Measurement Requirements}

Several key measurements will be made during the experiment. They include measuring the axial force induced due to shearing and stretching of the elastic fluid, axial displacement of the translation stage, axial midplane diameter of the fluid filament, temperature of the fluid, and fluid filament shape and evolution. These measurements were the driver for the design of the Rheometer and are discussed in detailed in the hardware description section.

The SHERE glovebox investigation has 25 test points as defined in figure 3 . These 25 test points consist of 5 series of tests $(\mathrm{I}-\mathrm{V})$, each with a different stretch rate. Within each series, there are 5 different pre-shear rates. The following equations define the parameters that will be measured during each test.

Pre-Shear Rotation Rate:

$$
\Omega=\dot{\gamma}_{o} \frac{L_{O}}{R_{O}} \frac{60}{2 \pi}
$$




\begin{tabular}{|c|c|c|c|c|c|}
\hline & & & tretch ra & & \\
\hline & $\begin{array}{c}\mathrm{I} \\
\left(0.1 \mathrm{~s}^{-1}\right)\end{array}$ & $\begin{array}{c}\text { II } \\
\left(0.3 \mathrm{~s}^{-1}\right)\end{array}$ & $\begin{array}{c}\text { III } \\
\left(1.0 \mathrm{~s}^{-1}\right)\end{array}$ & $\begin{array}{c}\text { IV } \\
\left(3.0 \mathrm{~s}^{-1}\right)\end{array}$ & $\begin{array}{c}\mathrm{V} \\
\left(5.0 \mathrm{~s}^{-1}\right)\end{array}$ \\
\hline & 0.0 & 0.0 & 0.0 & 0.0 & 0.0 \\
\hline$\frac{\pi}{\sigma}$ & 1.0 & 1.0 & 1.0 & 1.0 & 1.0 \\
\hline$\stackrel{d}{2}$ & 10.0 & 10.0 & 10.0 & 10.0 & 10.0 \\
\hline & 30.0 & 30.0 & 30.0 & 30.0 & 30.0 \\
\hline & 50.0 & 50.0 & 50.0 & 50.0 & 50.0 \\
\hline
\end{tabular}

Figure 3.-SHERE glovebox investigation test matrix.

where $L_{o}=5 \mathrm{~mm}$ and $R_{o}=5 \mathrm{~mm}$ represent the initial length and velocity, respectively and $\dot{\gamma}$ is the shear rate.
Stretch Velocity:
$V(t)=L_{o}(\dot{\varepsilon}) e^{\dot{\varepsilon} t}$
Final Stretch Velocity:

$$
V_{f}=40 L_{o} \dot{\varepsilon}
$$

\section{Hardware Description}

\section{A. Hardware Design Parameters}

The science objective of SHERE is to investigate the effect of preshearing on the stress/strain response of a polymeric liquid being stretched in microgravity. The design of the hardware was guided by the following test conditions: Generate a smooth, bubble-free, cylindrical liquid bridge ( $5 \times 10 \varnothing \mathrm{mm} \pm 5 \%)$ between two flat endplates. Impose a homogeneous shear rate in the fluid by rotating one of the endplates in the range $0 \leq \Omega \leq 500 \mathrm{rpm} \pm 1 \%$ while holding the other plate stationary. Achieve target angular velocity within $100 \mathrm{~ms}$; stop rotation within $10 \mathrm{~ms}$ of starting elongational deformation. Impose an approximately homogeneous elongational deformation in the fluid by axially translating one endplate in an exponential manner to generate strain rates $(\dot{\varepsilon})$ in the range $0.1 \leq \dot{\varepsilon} \leq 5.0 \mathrm{~s}^{-1}$ while obtaining maximum Hencky strains in the range $3.5 \leq \varepsilon \leq 4.5$. Conduct tests within the temperature range $20 \leq T \leq 25^{\circ} \mathrm{C}\left(68 \leq T \leq 77^{\circ} \mathrm{F}\right)$.

Furthermore, the following measurement requirements were imposed on the hardware design: Measure the axial force induced due to shearing and stretching within the range of $|\mathrm{F}| \leq 10^{4}$ dyne \pm 50 dyne (10 \pm 0.05 grams-force). Measure the actual axial elongation of the fluid to within $\pm 0.05 \mathrm{~mm}$. Measure the axial midplane diameter of fluid filament within the range of $0.1 \leq D \leq 10 \mathrm{~mm} \pm 0.005 \mathrm{~mm}$. Measure the temperature $T$ of the fluid to within $\pm(0.5){ }^{\circ} \mathrm{C}$. Provide video of the fluid filament to adequately and accurately detect edges and measure axial profile $D(z)$ of the fluid column. Based on these requirements the SHERE Rheometer and Camera Arm were designed. Additional components in support of the experiment include the Interface Box, Cables, Keyboard, Tool Box, Fluid Modules, and Stowage Tray. A software application using LabVIEW was developed to operate this experiment. SHERE was designed and built to operate in the Microgravity Science Glovebox (MSG) on the ISS (fig. 4). A brief description of each SHERE equipment item follows.

\section{B. Rheometer}

The Rheometer is the heart of the SHERE experiment (see fig. 5) where the preshear, elongational deformation, midpoint radius, filament shape, tensile force, and temperature measurements are made. The main components within the Rheometer include a rotational stepper motor mounted on a linear translation stage (slider), axial position sensor, laser micrometer, force transducer, electroluminescent (EL) panel, X-Y positioning stage, force transducer zeroing potentiometer, and thermistors. A Fluid Module is inserted between two quick-connect mounts-one fixed and the other movable. The covers of the Fluid Module are removed to allow a small quantity of fluid to be deployed between two flat plates. The X-Y stage can be used to make sure both flat plates are exactly aligned with 


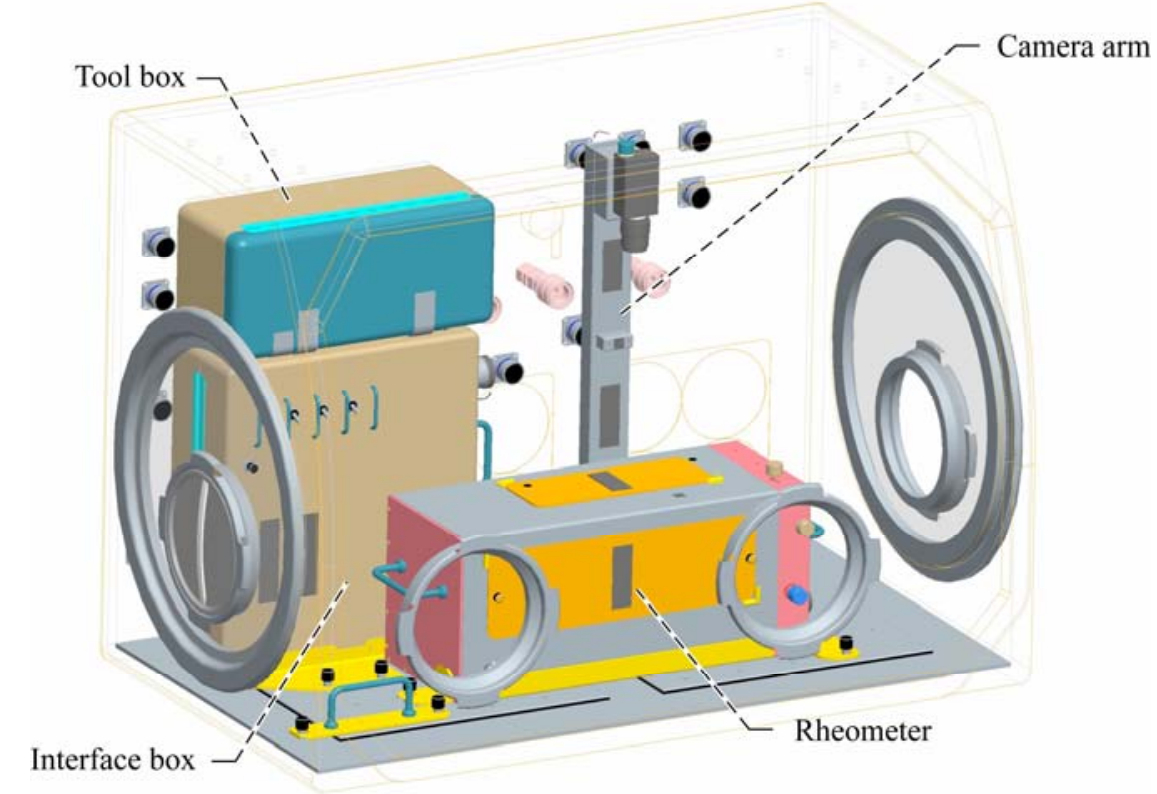

Figure 4.-SHERE Rheometer, camera arm, interface box and tool box inside MSG facility.

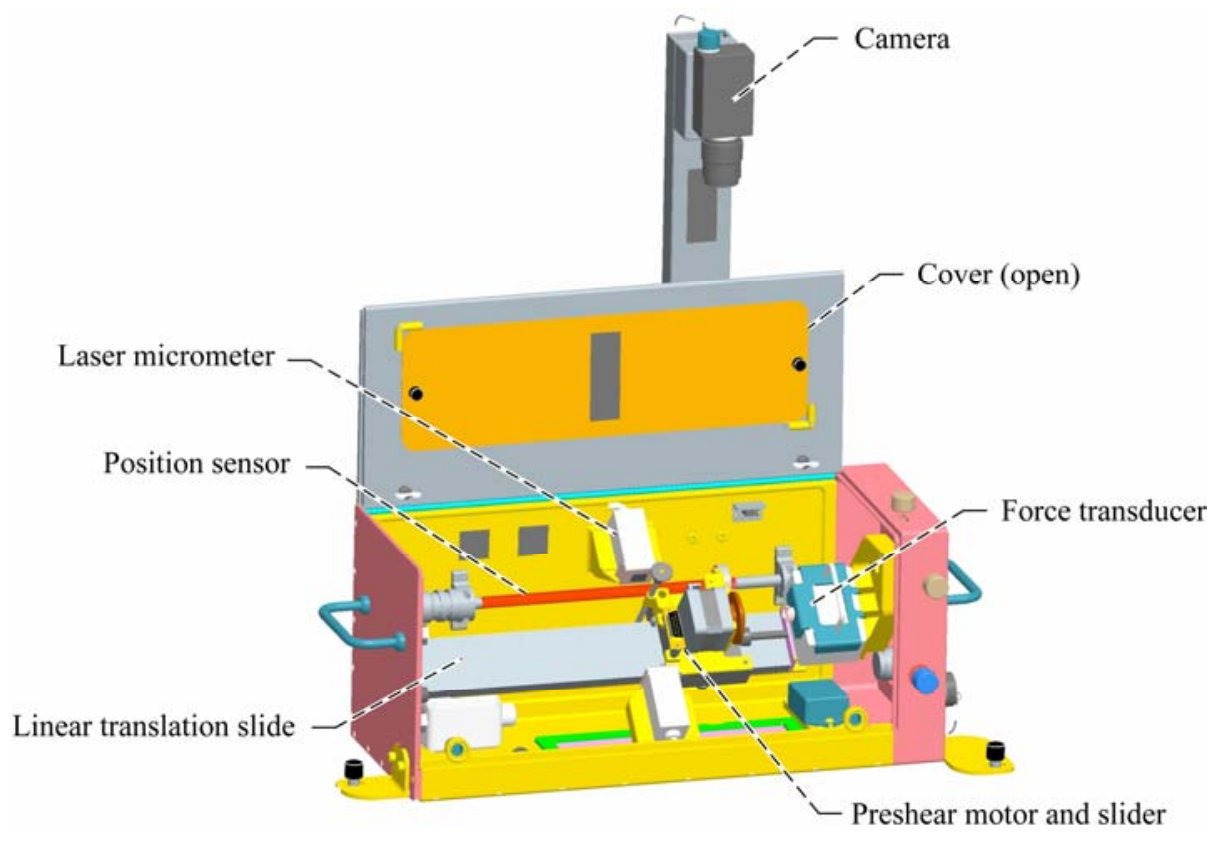

Figure 5.- Rheometer with cover (open) and showing force transducer, preshear motor and slider, linear translation slide, position sensor, laser micrometer, and camera.

each other. The fluid is then sheared by the rotational stepper motor at a pre-programmed rate and duration. The stepper motor has a maximum commanded rotation rate of $500 \mathrm{rpm}$. The rotation is then stopped, and the slider is moved away from the stationary plate with an exponentially increasing velocity profile, which yields a constant strain rate for the entire stretch throughout the deforming filament. The maximum translational velocity of the slider is $40 \mathrm{in} / \mathrm{s}$. The slide travel is limited by bumpers and end structure of the Rheometer. The tensile force during the elongation and after stopping is monitored with a high accuracy force transducer attached to the stationary plate. 
This transducer is a custom device manufactured for the SHERE project by Futek, Inc., which has previous experience working with NASA on high-accuracy rheometry measurements. The position of the moving plate is recorded over time by the axial position sensor to verify the imposed velocity profile. By backlighting the test fluid with an EL panel and viewing the fluid column from above with a video camera, half of the fluid column's shape is recorded for later analyses and simulations. Additionally, the fluid diameter is recorded after full extension via a laser micrometer at the column's midpoint. Fluid and air temperatures are digitally recorded from thermistors. The Rheometer is shown in figure 4 with the Camera Arm mounted to it. A folding cover with top and front viewing windows provides a level of containment of the fluid inside the Rheometer. The cover is secured using two captive 1/4-turn fasteners. The Rheometer housing material is aluminum alloy 6061-T6, and the top and front viewing windows are polycarbonate Lexan (General Electric). A special optical coating on each window is used to prevent the laser micrometer light from escaping, and two interlock switches cut power to the micrometer if the cover is opened. Each window is protected by a removable cover held in place with two captive fasteners.

\section{Camera Arm}

The Camera Arm attaches to the back of the Rheometer using two captive 1/4-turn fasteners. A black and white video camera is mounted to the top of the arm viewing down through the top window of the Rheometer. It provides a view of more than half of the filament length closest to the stationary flat plate. The filament is viewed as a silhouette with the EL panel providing as a soft uniform backlight. Power for the camera is derived from the SHERE Interface Box. The Camera Arm materials are aluminum alloy 6061-T6 and 6063.

\section{Interface Box and Cables}

The Interface Box provides power distribution and control for all components as well as data acquisition and storage. The Interface Box contains DC-DC converters, a motor controller, two motor drivers, signal conditioning, video boards, and an embedded processor. The Interface Box material is aluminum alloy 6061-T6. SHERE has seven electrical cables providing power and signal interconnections between the Rheometer, Interface Box, Camera Arm, and MSG.

\section{E. Fluid Modules and Stowage Tray}

SHERE will launch twenty-five Fluid Modules stored in a Stowage Tray. The Fluid Modules (fig. 6) are twolayered, cylindrical containers for the non-Newtonian Boger fluid samples. The outer shell protects the inner shroud, which is slid back to deploy the fluid column between two end plates. Each Fluid Module has a thermistor that is connected to the Rheometer when it is installed for monitoring the fluid temperature. The Fluid Module endplate

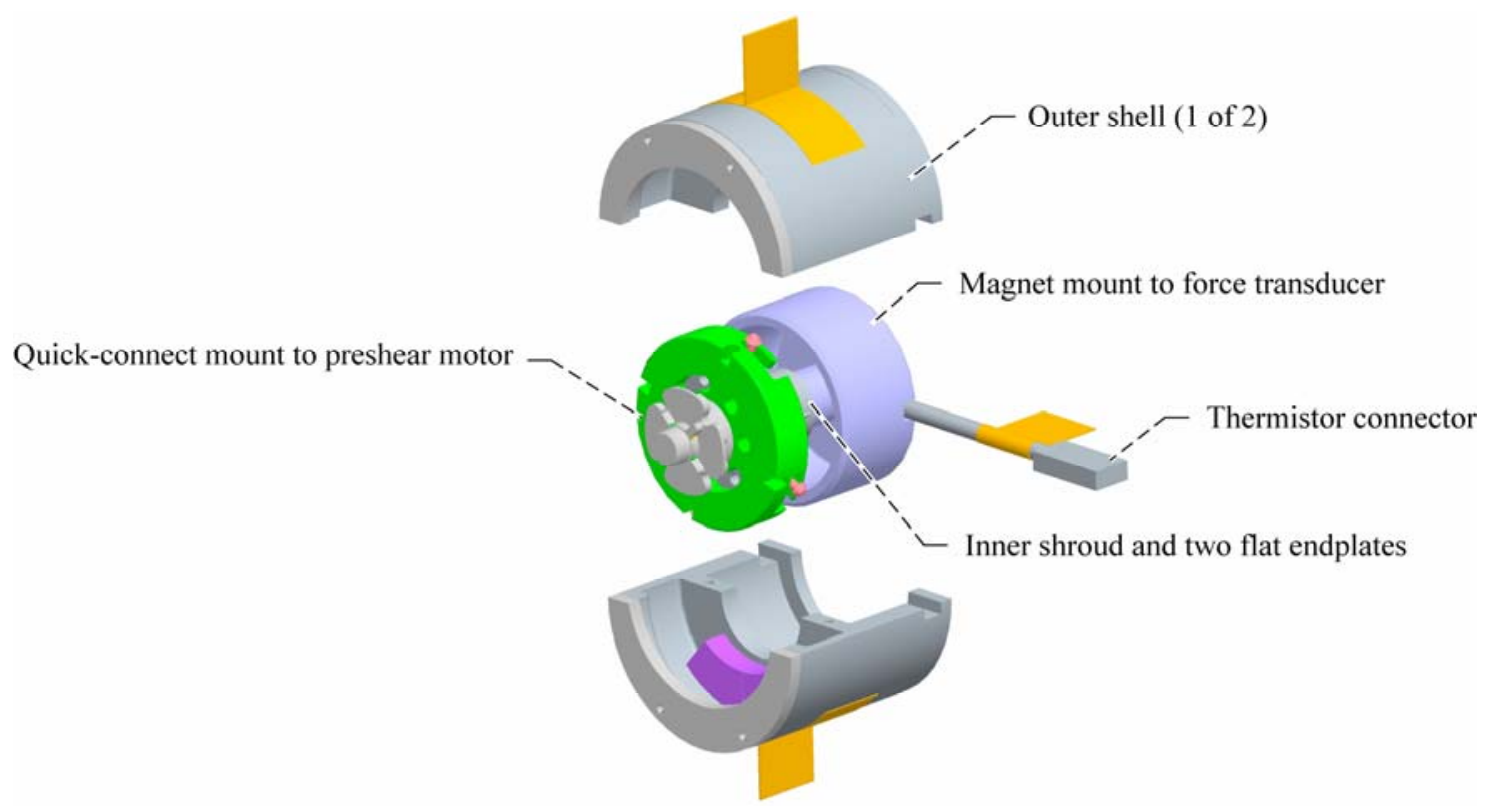

Figure 6. - Exploded view of fluid module. 
attached to the preshear motor is connected via a custom-designed quick connect. This end is rotated for a preset period of time and then translated to create an elongate fluid column. The Fluid Module endplate attached to the force transducer is connected via a magnet. It is stationary throughout the experiment. At the end of each experiment, the Fluid Module is closed and re-stored. The Fluid Modules are packaged in a 5x3 array in two layers inside the Fluid Module Stowage Tray. The Fluid Modules are made of aluminum alloy 6061-T6, and the Stowage Tray is aluminum alloy 6061-T6, stainless steel alloy 410, and filled with LD33 Plastazote foam. The Stowage Tray will be stored on-orbit in a temperature-controlled facility, either the Single-Locker Thermal Enclosure System (STES) or the Commercial Generic Bioprocessing Apparatus (CGBA), at $20 \pm 1{ }^{\circ} \mathrm{C}$ to establish the required fluid temperature prior to testing. This tray will also be used to hold the Fluid Modules for launch and regular stowage. Each individual Fluid Module will be sealed in a bag as an additional level of containment. Long duration testing has been conducted on the Fluid Modules over several years to ensure the fluid will not leak while in storage on the ISS. Additional testing is also needed to ensure the fluid samples can be successfully deployed after being stored for a long period of time.

\section{F. Tool Box}

The Tool Box contains miscellaneous parts and tools used during the setup and operation of the experiment. It also serves as a temporary storage location for various parts that are removed from the Rheometer during experiment operations. It is made of aluminum alloy 3003-T0, filled with LD33 Plastazote foam, and is mounted by Velcro (Velcro Industries B.V.) strips to the top of the Interface Box when inside the MSG. The following tools are contained inside the Tool Box: the Fluid Module Deployment Tool, Fluid Module Closing Tool, Fluid Module Holding Tool, Disk Alignment Tool, Camera Scale and Focusing Target, Laser Micrometer Calibration Target, Force Transducer Calibration Tool, Magnet Removal Tool and the Fluid Cleanup Material. The lid is held open by a Velcro pad when inside the MSG and is secured by Velcro strips when closed.

\section{G. Keyboard}

The Keyboard is used by the crew for data entry and experiment control. It is attached to a Bogen (Bogen Communications, Inc.) arm outside the MSG Work Volume (WV). The Keyboard is housed inside an aluminum alloy 3003-T0 box with a hinged lid. The lid allows access to the keyboard when opened and protects the keyboard from inadvertent operations when closed. The lid has a locking latch when opened and is secured by Velcro strips when closed.

\section{H. Software}

SHERE has developed a LabVIEW application to operate the experiment. The application executes on the Embedded Processor (EP) inside the Interface Box. The software allows for data entry and experiment parameter selection by the crew and also controls the hardware operation for initial setup tasks, experiment execution and data acquisition. The EP generates data screens that are combined with the video signal from the camera to create a single data display used by the crew for experiment setup/control. The data screen is also recorded on the MSG video recorders, and downlinked for realtime experiment observation on the ground. Experiment data is also recorded by the EP and stored on a PCMCIA card for later download. This data is then periodically transferred to the MSG Laptop Computer (MLC) for downlink to the ground for detailed analysis.

\section{MSG Interfaces}

Since SHERE will operate at the ambient MSG temperature provided by air circulation, this may impact the temperature control requirement. Therefore, SHERE will stow its Fluid Modules in the temperature-controlled facility of the STES) or CGBA for at least $24 \mathrm{hr}$ prior to use. The Fluid Modules will be inside the Stowage Tray, which is designed for use in either temperature-controlled facility.

The SHERE Rheometer (with attached camera arm) and Interface Box (with attached Tool Box) will be installed on the bottom plate in the MSG WV via two hard mounts for each component. Captive screw fasteners will be used in each case.

SHERE will receive +28VDC from the MSG to the Interface Box. This power is conditioned within the Interface Box to provide the required voltages to the SHERE components. The Interface Box provides circuit protection for the incoming +28VDC power via a 3A circuit breaker. All power to the Rheometer, Camera Arm and Keyboard passes through the Interface Box. 
The Interface Box interfaces to the MLC via an RS232 serial communication link. This interface is used to transfer data files to the MLC for later downlink to the ground during operations. Ground commands to the MSG will be performed to downlink of these data files.

An RS-170A video signal interfaces to the MSG video system. The video signal will be recorded on the MSG DV-CAM recorders, downlinked to the ground for realtime experiment observation, and displayed on one of the MSG video monitors for crew usage.

\section{Experiment Operations}

\section{A. Detailed Operations}

On-orbit SHERE operations will consist of hardware installation, hardware turn-on, hardware checkout, fluid sample installation, experiment execution, fluid sample removal and hardware removal. Also, for long periods of down time, a hardware shutdown procedure may be employed. SHERE will be in a soft stowage configuration for launch and landing.

The Fluid Modules are stored at $20^{\circ} \mathrm{C}$ for at least $24 \mathrm{hr}$ prior to testing. After the hardware is installed in the MSG, the experiment goes through a set of initial checkout and calibration procedures. Once these procedures are complete, one Fluid Module is installed in the Rheometer, the outside shells of the Fluid Module are removed and the inner shroud is slid back to expose the Boger fluid. The preshear motor is then rotated at a slow $100 \mathrm{rpm}$, and a stable fluid column is verified. Horizontal and vertical X-Y position controls are available as necessary to achieve a stable column. After stopping the slow column rotation, the force transducer reading is zeroed using an adjustment knob on the Rheometer.

A test point is then selected (preshear and strain rates), and the experiment automatically executes. The fluid is presheared and stretched according to a pre-programmed exponential velocity profile. The stretch is stopped abruptly at $194 \mathrm{~mm}$ in length, and the fluid is allowed to relax. Each experiment lasts approximately $5 \mathrm{~min}$, most of which is spent waiting for the fluid column to drain to the end plates and eventually breaks in the middle.

Afterwards, the translation slider is repositioned to the starting position, and the fluid column is recombined. If it is reusable due to criteria based on temperature, bubble contamination, and previous strain encountered, then another test can be performed with the same Fluid Module. Otherwise, the Fluid Module is removed, and the next one is installed for the next test.

\section{B. Crew Operations}

On-orbit crew interaction involves crew procedures guiding the installation/removal of the SHERE hardware in the MSG WV, mating/demating of cables, Fluid Module installation/removal with thermistor connection, and experiment setup/execution operations. All cabling will be properly labeled and keyed to prevent mismating. All voltages encountered are less than 32VDC, and no live connections are made with the exception of the Fluid Module thermistor connection to the Rheometer. Knobs and switches are designed to provide enough clearance for crew usage.

A trainer unit was designed, fabricated and built that is almost identical to the SHERE flight hardware unit. It will be used to familiarize the crew in the operations of the SHERE hardware. It was also used as a working engineering model during the assembly process for SHERE.

\section{In-Situ Fabrication and Repair Applications}

In the area of space exploration, the development of in-situ fabrication technology (a means of building new parts or replacing existing parts or tools) represents a critical element in the evolution of autonomous exploration capability. These parts, which include both new and recycled materials, will consist of plastics, polymers, metals, ceramics and composites. SHERE plays a role in this area in that it will be measuring a material property that has a direct connection to in-situ manufacturing and fabrication of polymer parts. Understanding extensional rheology is key in understanding how to process, for example, thermoplastic elastomers (flexible elastic polymeric materials) which are very resilient and can be made very thin (and hence light). This has tremendous benefit in future space missions where weight plays a critical role in the overall cost of a mission. Additionally, in-situ repair and nondestructive evaluation (NDE) technologies provide a means of repairing systems during transport and while on the Moon, Mars, and other extraterrestrial bodies. Multimaterial adhesives and fillers provide for a wide variety of repair applications such as applying adhesives under a reduced gravity environment for repairs of space suits or other materials. Ground-based work done by Professor Gareth McKinley using the filament stretching rheometer involves the investigations of cohesive and adhesive instabilities which manifests itself in concepts such as adhesion 
and tackiness of a material (ref. 2). SHERE has the capability to provide data for engineering design tools needed for polymer parts manufacturing systems to ensure their rheological properties have not been impacted in the variable gravity environment.

\section{Conclusion}

The SHERE flight hardware has been completed but has not been manifested, i.e., assigned to a Shuttle mission that will visit the ISS. While it is not known if SHERE will fly, numerous papers, presentations and conference talks have been written or given as a result of the ground-based testing done at the NASA Glenn Research Center and at the principal investigator's laboratory at MIT. This paper is a summary of the capability of the SHERE glovebox investigation and discusses SHERE's potential impact for in-situ fabrication and repair during future space exploration initiatives.

\section{References}

1. McKinley, G.H. and Sridhar, T., "Filament Stretching Rheometry of Complex Fluids," Annual Review of Fluid Mechanics, Vol. 34, Annual Reviews Press, Palo Alto, 2002, 375-415.

2. McKinley, G.H. "Preshear History and Uniaxial Elongation in a Microfilament Extensional Rheometer"proposal to GMX/MIM Program, NASA Lewis Research Center, January 30, 1997. 


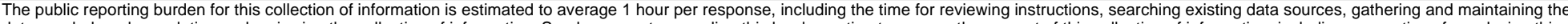

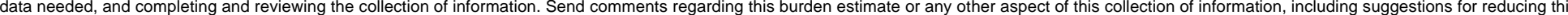

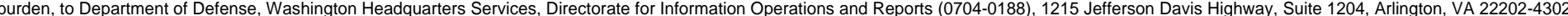

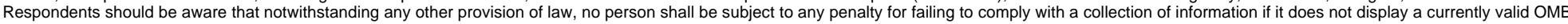
control number.

PLEASE DO NOT RETURN YOUR FORM TO THE ABOVE ADDRESS

\section{REPORT DATE (DD-MM- $Y Y Y Y)$ \\ 2. REPORT TYPE \\ 3. DATES COVERED (From - To)}

01-11-2007

\section{TITLE AND SUBTITLE}

Technical Memorandum

Shear History Extensional Rheology Experiment: A Proposed ISS Experiment

5a. CONTRACT NUMBER

5b. GRANT NUMBER

5c. PROGRAM ELEMENT NUMBER

6. AUTHOR(S)

Hall, Nancy, R.; Logsdon, Kirk, A.; Magee, Kevin, S.

\section{5d. PROJECT NUMBER}

5e. TASK NUMBER

5f. WORK UNIT NUMBER

WBS 516572.08.02

8. PERFORMING ORGANIZATION

REPORT NUMBER

E-15433

National Aeronautics and Space Administration

John H. Glenn Research Center at Lewis Field

Cleveland, Ohio 44135-3191

\section{SPONSORING/MONITORING AGENCY NAME(S) AND ADDRESS(ES)}

National Aeronautics and Space Administration

Washington, DC 20546-0001

\begin{tabular}{|c|}
\hline $\begin{array}{l}\text { ACRONYM(S) } \\
\text { NASA }\end{array}$ \\
\hline $\begin{array}{l}\text { 11. SPONSORING/MONITORING } \\
\text { REPORT NUMBER } \\
\text { NASA/TM-2007-214098; AIAA-2006 } \\
\end{array}$ \\
\hline
\end{tabular}

\section{DISTRIBUTIONIAVAILABILITY STATEMENT}

Unclassified-Unlimited

Subject Categories: 29 and 23

Available electronically at http://gltrs.grc.nasa.gov

This publication is available from the NASA Center for AeroSpace Information, 301-621-0390

\section{SUPPLEMENTARY NOTES}

\section{ABSTRACT}

The Shear History Extensional Rheology Experiment (SHERE) is a proposed International Space Station (ISS) glovebox experiment designed to study the effect of preshear on the transient evolution of the microstructure and viscoelastic tensile stresses for monodisperse dilute polymer solutions. Collectively referred to as "Boger fluids," these polymer solutions have become a popular choice for rheological studies of non-Newtonian fluids and are the non-Newtonian fluid used in this experiment. The SHERE hardware consists of the Rheometer, Camera Arm, Interface Box, Cabling, Keyboard, Tool Box, Fluid Modules, and Stowage Tray. Each component will be described in detail in this paper. In the area of space exploration, the development of in-situ fabrication and repair technology represents a critical element in evolution of autonomous exploration capability. SHERE has the capability to provide data for engineering design tools needed for polymer parts manufacturing systems to ensure their rheological properties have not been impacted in the variable gravity environment and this will be briefly addressed.

\section{SUBJECT TERMS}

Rheology; Rheometers; Polymer; Shear flow; Stretching; Elongation

\begin{tabular}{|l|l|l|l|}
\hline \multicolumn{2}{|l|}{ 16. SECURITY CLASSIFICATION OF: } & $\begin{array}{l}\text { 17. LIMITATION OF } \\
\text { ABSTRACT }\end{array}$ \\
\begin{tabular}{|l|l|} 
a. REPORT & b. ABSTRACT \\
$U$
\end{tabular} & $\begin{array}{l}\text { c. THIS } \\
\text { PAGE } \\
\text { U }\end{array}$ & UU \\
\hline
\end{tabular}

18. NUMBER
OF
PAGES
15
19a. NAME OF RESPONSIBLE PERSON STI Help Desk (email:help@sti.nasa.gov) 19b. TELEPHONE NUMBER (include area code) 301-621-0390



